\title{
Behaviour Computer Animation, Communicability and Education for All
}

\author{
Francisco V. Cipolla Ficarra ${ }^{1,2}$, Jacqueline Alma ${ }^{3}$, and Miguel Cipolla-Ficarra ${ }^{2}$ \\ HCI Lab. - F\&F Multimedia Communic@tions Corp. \\ ${ }^{1}$ ALAIPO: Asociación Latina de Interacción Persona-Ordenador \\ ${ }^{2}$ AINCI: Asociación Internacional de la Comunicación Interactiva \\ ${ }^{3}$ Universidad Nacional de La Pampa \\ Via Pascoli, S. 15 - CP 7, 24121 Bergamo, Italy \\ ficarra@alaipo.com, jacqueline_alma@yahoo.com, ficarra@ainci.com
}

\begin{abstract}
We are making a heuristic study to determine the benefits of computer animation to improve communicability in the educational processes. A diachronic analysis allows to research the influence of the design of the first animations of the 20th century on the current $2 \mathrm{D}$ and/or 3D characters. We are also examining the existing link between the artistic and technical context at the moment of carrying out computer animations. Finally, the results of a heuristic assessment of 2D and/or 3D characters with and without artificial intelligence components in the last two decades in Spain and Italy are presented.
\end{abstract}

Keywords: Behaviour Computer Animation, Education, Communicability, Computer Graphics, Multimedia, Evaluation.

\section{Introduction}

In the last few years we have been watching an almost perfect realisation of virtual characters or 3D animations on video consoles, computer screens, mass media communication, etc. [1] [2] [3] that make it hard to differentiate whether they are real human figures or not. This degree of the quality of the computer-made images applied to virtual tutors in e-learning courses prompts a rhetorical question: Are human beings ready to accept that the concepts are $100 \%$ taught by virtual characters, considering the realism of these "professors", or will the characters continue to fulfil merely an assistance role in the learning process? Currently, because of economic cost in many national or private firms in the area of telecommunications, these virtual characters are steadily usurping real people's tasks. However, automatic on-line information systems, for instance, do not solve veraciously the problems that users have, such as the non-functioning of an Internet service [4].

Additionally, the quality control systems of those services are not published on the websites of these telecommunications companies. Consequently, it is not possible to know for sure whether the result of inserting the virtual characters as assistants in front of users with real problems of non-functioning services is a positive result or not [4]. These virtual assistants are also starting to appear in the college environments for 
information and orientation tasks within the portal structure. Others, in contrast, have been used with didactical purposes for a long time, especially in the industrial context. In both cases we see how, little by little, there is a move from characters taken from comic books to more and more real characters, who have gone on to assist adult users, as well as young and adolescent users. In this process of continuous evolution in the area of communicability of interactive systems, we are trying to detect in the current work those elements that may contribute through an excellent quality of visual realism and synchronized movements to a greater integration of those characters in the whole educational process, from childhood right through till the continuous training of adults [5].

Addtionally, there will be an attempt to research the details of the elements that currently bolster the communicability of those characters, bearing in mind not only the on-line and off-line multimedia interactive systems, but also social mass-media. At the same time, a state-of-the-art of behavioural computer animation from its origins up to the present day will be drawn in order to detect which components of graphic computing bolster communicability. For example: the parts of the body of those characters which are frequently used, compared to those deriving from cinematic computer animation; the instruments and means of traditional teaching available for help with difficulties in the learning process; the behavioural style and the different personalities that can be assumed in relation to the context or environment in which users interact, and the personalization of the tutor by the potential users of the interactive systems. The latter, in relation to age, education and the knowledge/experience in the use of computers and motivation for attending the courses or contents taught by these characters. The different e-learning experiences, campus and virtual classrooms, etc. that we are trying to compile in our work will enable us to answer the rhetorical question we have stated. This answer will allow us to set up a series of research themes both for the immediate future and the long term, via Web 2.0 and more especially via Web 3.0

\section{A Diachronic Study about Pioneers and First Animations}

In the traditional animation literature, Emil Cohl is the pioneer who is always mentioned since its dawn [6]. He was a newspaper cartoonist who entered film production in 1905. Cohl applied the principle of the comic strip to the screen. "Fantasmagorie" [6] represents without any doubt the greatest expression in the metamorphosis of the characters. Besides, it is the intersection of the real world with the virtual world because you can see the hands of the makers of the drawings.

Therefore, there is in that work as in the other works of the time the emulation and simulation of reality [7]. These are principles that would be transferred to computers. Another of the historic novelties of Cohl and his work team was the technique of stopmotion photography which would set up the basis of the current "stop action" in computers. Moving or physically manipulating objects and setting up each one of the pictures or frames in relation to the television 25 frames per second or 24 frames per second in the cinema, the viewer perceives the objects in motion.

In this context it is worth mentioning the work of Cohl in "The Dentures" in 1909 [6]. Perhaps the most accomplished in the history of animation in that decade 
"Mobelier Fidele" (The Automatic Moving Company) in 1910 where Cohl breathes life into an automatic moving (chairs, tables, lamps, baskets, etc.) move of their own accord. Another of the great subjects of those times was transoceanic communications. In this set of works we have "Professor Bonehead is Shipwrecked" by Emil Cohl. It was in these animations where many animators of those times focused to give movement to water. Certainly, works of few minutes runtime would entail many weeks of work for the production team.

Nowadays, commercial programs such as Maya incorporate the wave effect of water or movement of liquids, as one among many options. However, in the beginning animators required several tricks or effects to achieve those results, and have an artistic unity to coordinate the draughtsmen in order to generate a style of homogenous design in the drawings that later on would be animated. Something that even nowadays exists in the comics, especially with US, British and Japanese classical characters, such as: Astro Boy, Snoopy, The Flintstones, The Simpsons, Dragon Ball, etc.

Gertie, the Dinosaur (1914) a 12 minutes animation by Winsor McCay laid down [6], perhaps for the first time, the foundations of behaviour animation of a living animal, from which there were no direct references of movement. That is, that animation set a landmark in the history of animation and consequently of the current computer animation. That moment of giving a personality through movement to beings extinguished millions of years ago opened a long path of research and development where the animators needed work teams made up by a great number of professionals hailing from the most diverse disciplines. It is not for nothing that the vast majority of computer animation works that have won the movie Oscars have professionals from the physical sciences, computer programmers, mathematicians devoted to develop algorithms for graphic computing, fine arts artists, set designers, dress designers, historians to recreate scenes, botanists, meteorologists, astronomers, etc. who work on the characters and on the environment where these characters appear. These professionals may join on a steady basis the work staff or be external collaborators on a constant basis.

In these works we find the current foundations to carry out animations such as can be photography, montage techniques, the first special effects, etc. Although these works sprang from vignettes in the newspapers, in the case of Felix the Cat [8] or true events, such as "The Sinking of the Lusitania", by Winsor McCay [6]. In many works there was a textual reference, that is, traditional tales that were animated by introducing the Felix character. In this case, creativity was more focused on the technical aspects of the novel means like the effect of metamorphosis than on the storyboard.

A metamorphosis has always been very popular in the animal computer animations, especially in the advertisement or cinema environment. Metamorphosis still remains a valid resource to draw the attention of the potential users of interactive systems, regardless of the goal of the use of the computer. Obviously these early works had incorporated the text in the shape of comic balloons, since they stemmed from the comic. Besides, the movies were silent, and in the theatres in which these early animations were shown, they were generally accompanied by music instruments, such as the piano. In the case of "The Sinking of the Lusitania", the story is based on a real event. In this case each and every one of the 25,000 drawings that 
make up the animation were photographed. Besides, the context factor of the story took an essential role in the set design such as the animation of the water waves, while the sky was static. The theatrical factor was present in the animation since there was a curtain that opened up to give start to the animation. In order to give a greater realism to the narrative, some pictures of the passengers of the ship were included. The value of the static photography inside a dynamic means boosts the idea of diachronism and synchronism.

In the cartoon "Puss in Boots" by Walt Disney real image were combined with 2D animations [6] [9]. That is, animated characters that got out of the drawing sheet, and came into contact with the draughtsman's environment. It was even combined with plasticine sculptures. That is, with the animations of the sculptures and photographing the movements of the characters and in the milieu, photogram by photogram, just like the current Wallace \& Gromit works, "Chicken Run", etc.

\subsection{Mass Media and Animations Evolution}

The dawn of the past century hit a landmark in the evolution of the animations linked to the constant breakthroughs of the social communications of that time. A short synthesis of those first 40 years can be listed in the following way (in brackets are the author/s and/or the dates of the presented events [8] [9] [10]:

- The first humour comic animation cartoons appear in 2D (Blackton, 1907).

- The first experiments of TV start in Russia (Boris Rosing, 1907).

- Animation of a comic strip published in a New York newspaper, whose main character was Little Nemo (Winsor McCay, 1911).

- The first experiments of synchronizing the sound to the movie images begin (Gaumont, 1912).

- The expression "animated cartoons" is coined in the film 'Newly weds' (Emil Cohl, 1912).

- Experiments and/or discoveries with the first effects of cinematographic camera: accelerated motion, slowed down, reverted or backwards, images fading, etc. (1913).

- Appearance of the first colour animated cartoons. It was the debut of Thomas Cat (John Bray, 1920).

- Incorporation of the key frame techniques in the cinema animations (Disney, 1926).

- Presentation of montage theory with the classical film 'Battleship Potemkin' (Sergei Eisenstein, 1926).

- Invention of the cinemascope, whose use will spread in 1953 (Chretien, 1928).

- Presentation of the 16 mm. Kodakcolor film (Eastman Kodak, 1928).

- The first TV channel is inaugurated in Washington DC 'W3XK' (Jenkins, 1928).

- Felix the Cat is the first cartoon that appears in the New York television station NBC (1928).

- Dinner Time was the first cartoon with sound, voice and music (Paul Terry, 1928).

- Premiere of the first Disney film in the Colony Theatre of New York (1928).

- Use of a system of photomechanical coloration in the film 'King of Jazz' (Walter Lantz, 1930).

- Use of the Technicolor in the animations 'Flowers and Trees' gets the first Oscar (Disney, 1932). 
- Eastman Kodak presents the first $8 \mathrm{~mm}$ film (1932).

- The first TV educational network appears in the University of Iowa: W9XL (1932).

- The Three Little Pigs is the first cartoon designed with a storyboard (Disney, 1933).

- 'Fantasia' was the pioneering film in the use of stereophonic sound (Disney, 1941).

In this listing are the keys of the audiovisual which in the late 80s and early 90 s would move into the computer screens, from the workstations in the computer animation industries to the desktops of the users keen on the images in motion (2D and/or 3D). The main sectors since the origins of animation can be depicted through the following ellipsis and in the middle we would place animation.

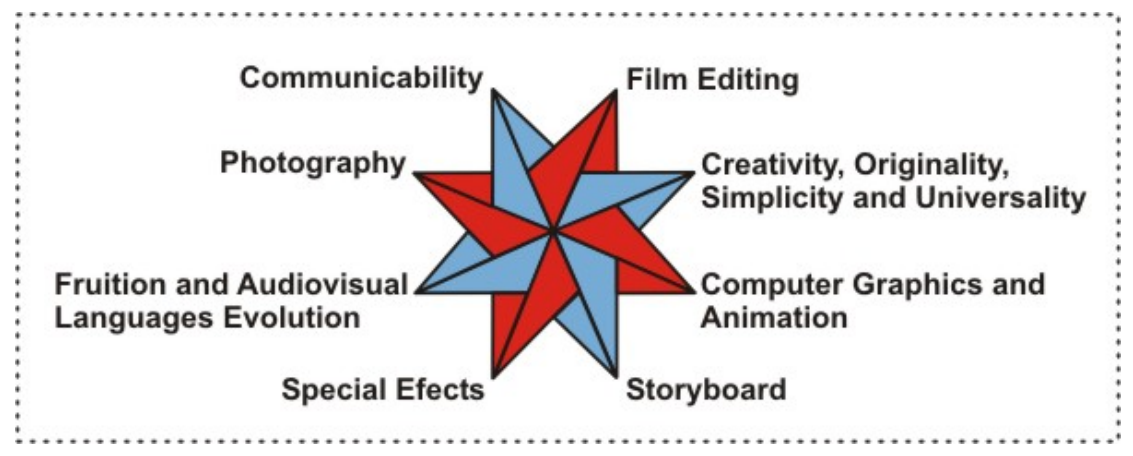

Fig. 1. Each one of the points of this star depicts an area of traditional animation

In principle that star has sectors of traditional animation which are redundant or duplicate, but with the passing of time some of them have converged among themselves, linking each other indefinitely, such as can be the coloration of images through the computers. That is, resorting to commercial programs of self-edition such as can be Photoshop or Photo-Paint. However, what has remained unchanged since the origins is the differentiation between the creative or artistic sectors and the technological [11]. Clearly these are two split sectors.

There may be intersections between them but the technological sector has been taking up a bigger area inside the set of elements that make up the artistic objects. For instance, the possibility of making the drawings directly on the computer without the need of drawing traditionally, that is, by hand and then moving those drawings to the computer through the use of the scanner.

This division of sectors has found several solutions of its own depending on the geographical environment where the computer animations are made.

In the previous examples of the early 20th century were already the foundations of the computer animation cinematographic industry, whose success or failure derives from many factors such as:

- Achieving the communicability of the contents, for instance, resorting to the style guidelines to avoid the confrontation between the localization and the globalization of the explicit and implicit message of the animations. 
- Resorting to the utmost simplicity of style to reach the greatest universality of the message and a wider national and international circulation in the least possible time.

- Differentiating between emulation and simulation of reality so that the user can identify with the characters and keep the attention and interest in the content that is presented in an interactive way; whether it is sequential or not.

- Generating work teams where the several disciplines and professionals agree on the actions in a democratic and balanced way.

- Keeping constantly the spirit of curiosity in the face of the audiovisual novelties, software, hardware, etc. by the members of the production team and establishing mechanisms of constructive discussion among all the members so that these breakthroughs can be evaluated for its later incorporation in the productive processes.

- Fostering the interest towards those pastimes that can improve the common dialogue between technicians and artists. For instance, a computer science expert who participates in photography courses and a virtual characters designer who attends the presentations of the latest versions of the software for computer animation and/or self-edition.

- Counting on communicability experts in each one of the production process stages, that is, from design until post-production.

- Defining quality attributes and aim them inside the cardinal points of computer animation, especially with the characters to whom they instill life and personality: universality, simplicity, originality and humour.

\section{Human Characters and Behaviour: Animations for Users}

The 2D animation deriving from comic like its evolution towards $3 \mathrm{D}$ and the later combination of 2D and 3D has made its importance in the educational process apparent.

Millions of students before starting to write or read have seen cartoons in the traditional communication media, that is, in print media, television and cinema [12] [13]. We can see an example in the following Snoopy abecedary (www.peanuts.com) [14]:

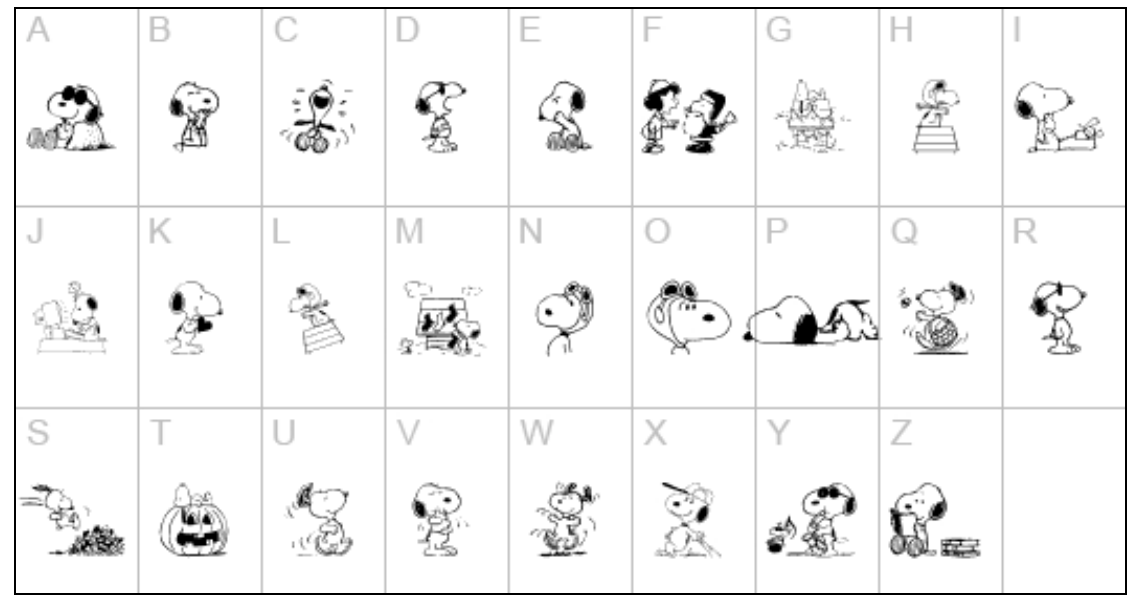

Fig. 2. Snoopy accompanies each one of the letters of the abecedary in different situations 
This possibility of associating something unknown such as the number or a letter with a sound through a character already known or seen on television or in magazines facilitates the reading learning process, especially among the youngest kids, as long as they know Snoopy. This character from the comic strips becomes automatically a guide or study mate - so to speak a virtual agent - for the children. Obviously, for reasons of social psychology, pedagogy, sociology, although we have a virtual agent of Snoopy in 3D, this can't replace the teacher in the classroom. A virtual agent can't take the place of the teacher in the first moments of the learning how to read, not only with the students in the nursery school or early courses even with those adults who can't read or write [14]. The virtual agents have a helping function in the educational process. In the industrial case they may have a role of constant support, in case of doubts about the usage of certain equipment, machinery, etc., or in situations which occur suddenly, with the need of making a quick decision.

As it almost always happens with the quality attributes in the communicative process, such as empathy, inference, self-evidence, etc., those virtual characters which are known beforehand by the users or viewers of the audiovisual contents know what is the behaviour of said characters. As it happens with self-evidence in an interactive system, the user has the feeling of gaining time in navigation, since he anticipates the design and the purpose of the components which are shown to him for the first time. The anticipation of meaning has a positive influence on another attribute of quality such as motivation. Self-evidence is essential to increase the trust in those users who lack previous experience in the use of the multimedia interactive systems, for instance, what prompts a greater motivation to keep on interacting with the system.

Traditionally, Kahn [15] divided self-evidence into several categories inside a hypermedia system: First, the navigation styles of the application of the different structures without getting acquainted with the whole system, that is, those navigation styles may be related to the permanent possibility of advancing or going backwards from a bidirectional guided link that is made up by a set of screens; second, the anticipation of the destination of a link from the original node (in the case of the nodes with definitions which are activated from the words that are underlined in a text); third, the understanding of the degree of control that is available in the active means to operate with them. The control is exerted through the forward, pause, backward keys, etc. However, Kahn excluded other components of self-evidence which are related to the category of the design known as presentation or layout such as certain constituents of the metaphor, to widen the dimension of the screen at the moment of watching a YouTube video or modifying the volume. That is, if in the context there are design isotopic lines, all those factors linked to the previous will help self-evidence and very specially the empathy and inference in the communicative

process. Some of these quality attributes have been the target of study and set in motion of projects related to the expert systems generated through artificial intelligence.

\subsection{Behaviour Computer Interaction, Artificial Intelligence and Education}

In the previous examples of the animations the user has always had a passive or active role in the face of the animations, whether as a receptor of the images on the cinema screen or the television or in the interactive process with computers. In this latter case, the main reasons why the user interacts may be to search for information, training, 
pastime (videogames) and social relationships. Now the Internet has incorporated in the last two decades the notions of artificial intelligence. Consequently, we have virtual agents or autonomous animated characters which can remain for some length of time without the dependence of the human being. That is, characters who act following the parameters or models that human beings use to make their decisions. These expert virtual agents are capable of solving problems in fractions of a minute, as long as they are not easy to solve by the human being (generating an expert system is not worth the trouble) or whether the problem is very big, since it requires strong investments in hardware.

The resolution of the problems must be based on experience and knowledge, leaving aside the random factor. Besides, the resolution of the problem must not be based on intuitive or common sense methods. All of that with the purpose of turning the expert agents into an ideal assistant to get complete information in the face of decision making.

In the case of on-line information such as the virtual tutors of the universities, phone information services, Internet, etc., endless communicability errors can be seen [4]. Errors which can be put down to their design stage, since they are based on intuitive aspects. From the point of view of the quality of the animation and graphic information, they have a low quality from the point of view of movement, textures, modelling, etc. This reality has lead us to carry out a study of the behaviour computer animation among the cinematographic, television, virtual tutors on-line and in the commercial and free-access on-line videogames, in the Spanish and Italian portals (300 randomly selected works). In the lower part are the quality attributes that refer mainly to the aspects of graphic computing (static and dynamic) and communicability. Besides, characters and virtual agents are synonyms in the figure 3 . The interested readers may find a wide definition of those notions in the following bibliographic references [16--20].

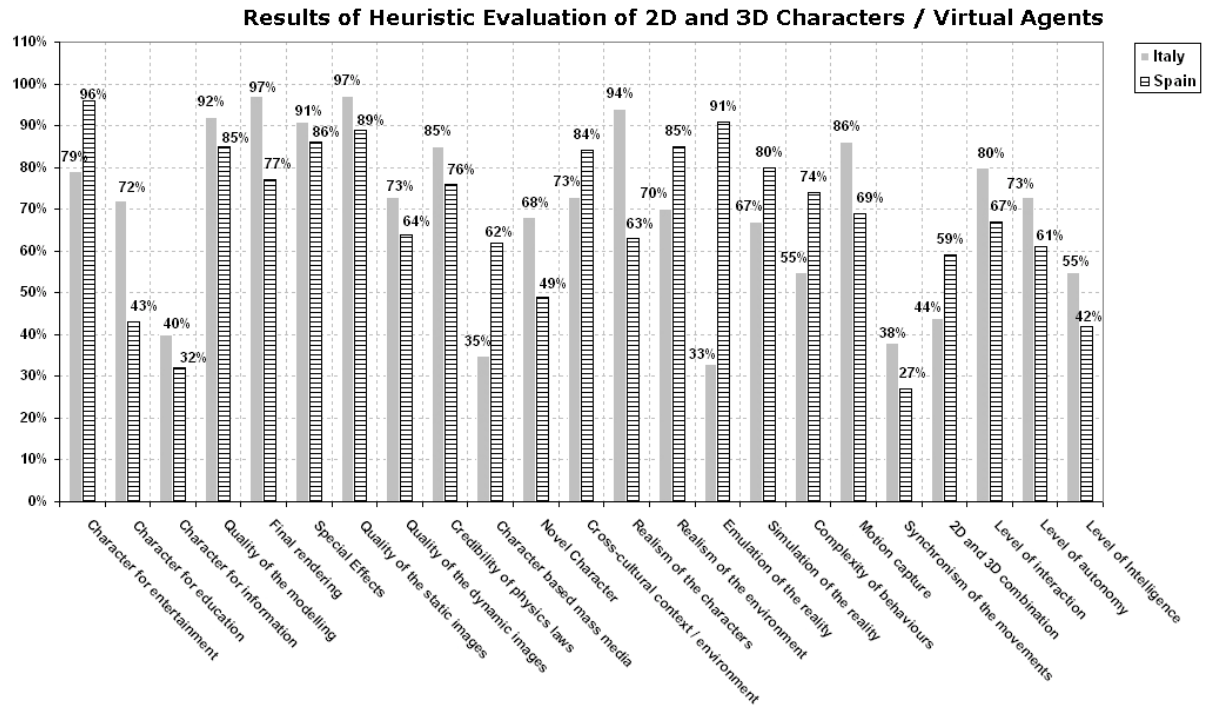

Fig. 3. The results make apparent the variability of the quality attributes between Italy and Spain 


\section{Conclusion}

The first animations in the social mass media underwent a parallel evolution to the breakthroughs in the technologies of those times. However, the foundations of the design for the animations have remained intact along the decades, even in the computer-made animations and in special effects. The key elements to draw the attention and prompt the motivation of the user or international viewer of the animations in cinema, television, computer, mobile phone, etc., are the creativity and the originality of the characters linked to the behaviour and character that they have at the moment of interacting with their virtual peers or with the user. Humour also needs to be included, the same as the simplicity in the communicability and the context where these characters move, 2D and/or 3D. In the multimedia interactive systems, the category of layout or presentation of the information generated through computer graphics play an essential role. In that category it is necessary to differentiate between the emulation or simulation of reality at the moment of designing and animating virtual characters. In the expert agents, it is necessary to add a middle level in the resolution of problems. The results reached in the heuristic evaluation make apparent the greater communicability in the characters for the entertainment rather than for education in Spain and Italy. Although the quality of the computer graphics, including the realism of movement, is greater in the Spanish systems. In the Spanish systems prevails the quality of the modelling. That is, there is a greater quality in the static images in Spain than in Italy. The final rendering (textures, lightening techniques, combination of colours, environmental effects, etc) and the refining of each one of the frames that make up a scene are better in Spain than in Italy. The quality of the behaviour computer animation in our universe of study along the last two decades has turned out to be low in both countries. The reason is the lack of interaction between the formal and the factual sciences in the university academic training and the industrial sector of the audiovisual.

\section{References}

1. Badler, N., et al.: Virtual Humans for Validating Maintenance Procedures. Communications of ACM 45(7), 56-63 (2002)

2. Scharver, C., et al.: Designing Cranial Implants in a Haptic Augmented Reality Environment. Communications of ACM 47(8), 32-39 (2004)

3. Lu, R., Zhang, S.: Automatic Generation of Computer Animation. Springer, Berlin (1998)

4. Barnes, M., Meyers, N.: Mobile Phones: Technology, Networks and User Issues. Nova Science Publishers, New York (2011)

5. Cipolla-Ficarra, F., Cipolla-Ficarra, M.: Computer Animation and Communicability in Multimedia System and Services: A Trichotomy Evaluation. In: Damiani, E., Jeong, J., Howlett, R.J., Jain, L.C. (eds.) New Directions in Intelligent Interactive Multimedia Systems and Services - 2. Studies in Computational Intelligence, vol. 226, pp. 103-115. Springer, Heidelberg (2009)

6. Video. Los comienzos de la animación. Divisa Ediciones, Valladolid (1995)

7. Cipolla-Ficarra, F., et al.: Human-Computer Interaction. Tourism and Cultural Heritage. Springer, Berlin (2011) 
8. Barrier, M.: Hollywood Cartoons: American Animation in Its Golden Age. Oxford University Press, Oxford (2003)

9. Bendazzi, G.: Cartoons: One Hundred Years of Cinema Animation. Indiana University Press, Indiana (1999)

10. Rosebush, J.: Historical Computer Animation. ACM Siggraph, New York (1992)

11. Cipolla-Ficarra, F., Nicol, E., Cipolla-Ficarra, M.: Computer Graphics and Mass Media: Communicability Analysis. In: Cipolla Ficarra, F.V., de Castro Lozano, C., Pérez Jiménez, M., Nicol, E., Kratky, A., Cipolla-Ficarra, M. (eds.) ADNTIIC 2010. LNCS, vol. 6616, pp. 182-192. Springer, Heidelberg (2011)

12. Wells, P.: The Animated Bestiary: Animals, Cartoons, and Culture. Rutgers University Press, New Jersey (2008)

13. Kerlow, I.: The art of 3D Computer Animation and Imaging. John Wiley, New York (2000)

14. Cipolla-Ficarra, F.: Heuristic Evaluation of Animated Help in Hypermedia. In: CD Proc. HCI International, Las Vegas (2005)

15. Kahn, P.: Global and Local Hypermedia Design in the Encyclopedia Africana. In: IWHD 1995, pp. 115-129. Springer, Berlin (1995)

16. Cipolla-Ficarra, F.: Eyes: A Virtual Assistant for Analysis of the Transparency and Accessibility in University Portal. In: CD Proc. Applied Human Factors and Ergonomics, Las Vegas (2008)

17. Cipolla-Ficarra, F.: Virtual Learning Environment: Quality Design for Foreign Languages in Multimedia Systems. In: Damiani, E., Jeong, J., Howlett, R.J., Jain, L.C. (eds.) New Directions in Intelligent Interactive Multimedia Systems and Services - 2. Studies in Computational Intelligence, vol. 226, pp. 117-127. Springer, Heidelberg (2009)

18. Cipolla-Ficarra, F., Cipolla-Ficarra, M., Vera, P.: Communicability for Virtual Learning: Evaluation. In: Jacko, J.A. (ed.) HCII 2009. LNCS, vol. 5613, pp. 68-77. Springer, Berlin (2009)

19. Cipolla-Ficarra, F.: Quality and Communicability for Interactive Hypermedia Systems: Concepts and Practices for Design. IGI Global, Hershey (2010)

20. Styliaras, G., Koukopoulos, D., Lazarinis, F.: Handbook of Research on Technologies and Cultural Heritage: Applications and Environments. IGI Global, Hershey (2011) 